\title{
Use of the Dry Chemistry "Reflotron" Blood Analyzer under Outdoor-Field Conditions in Veterinary Medicine
}

\author{
Carlos M. Lopes-Pereira ${ }^{1}$, Mohamed Harun ${ }^{1}$, Dagmar Schmidtova ${ }^{1}$, Inacio Timane ${ }^{1}$, Marcos Mabasso ${ }^{1}$, \\ Frank Otto ${ }^{1}$ and Eitan Bogin ${ }^{2}$ \\ 1 Veterinary Faculty, Eduardo Mondlane Úniversity, Maputo, Mozambique \\ 2 Kimron Veterinary Institute, Tel Aviv University School of Medicine, Bet Dagan, Israel
}

Summary: Adapting the concept of "bed-side" patient analysis, the Boehringer-Mannheim Reflotron ${ }^{\circledR}$ was evaluated for its possible use in veterinary medicine under outdoor-field conditions.

Horse blood was analysed with the Cobas Bio analyzer, and indoor and outdoor analyses were also performed with the Reflotron ${ }^{\circledR}$. All values showed close agreement with no significant differences. Good correlation coefficients ( $r$ values around 0.9000 ) were also seen between all methods used.

The Reflotron ${ }^{\circledR}$ was operated under outdoor-field conditions by using, whenever available, an on-farm electricity source, or a gas operated generator.

The data supports the proposal to adapt the Reflotron ${ }^{\circledR}$ (or any other proved system) for outdoor-field, patient-side blood analysis, thus providing the veterinary clinician with values for blood quantities, and enabling an improved and more complete diagnosis.

\section{Introduction}

Blood analysis for the diagnosis and prognosis of diseases, metabolic disorders, nutritional deficiencies or imbalances is a common practice in veterinary medicine $(1,2)$. In small animal practice, working conditions enable the use of a nearby indoor laboratory, and the results of blood analyses are available in a relatively short time. In large or small safari and farm animals, laboratory support for diagnosis is not readily available, and clinicians must often manage without laboratory services.

On-farm conditions are often very difficult, thus inhibiting the provision of laboratory services. The long distance to a service laboratory requires shipments under special conditions, often resulting in deterioration and spoilage of the specimen. There may be no access to energy sources for the operation of the analysis equipment, and the installation of appropriate facilities would incur additional costs. In any case, there is a lack of proper analyzing equipment capable of operation under harsh outdoor conditions (3-5).

Dry chemistry systems are, however, now available for patient bedside blood analysis, and these are easily moved from bedside to bedside around the hospital. We therefore investigated the possibility of adapting dry chemistry systems for on-farm animal-side blood analysis in veterinary medicine. A system for on-farm animal-side blood analysis could greatly improve diag- nosis by providing an immediate analysis during a farm visit, thus reducing the need for shipment over long distances, with the accompanying extra cost, risk of spoilage, and delayed response. Furthermore, the system seems to fit well the needs of the veterinary clinician because it is easy to operate, cheap, and small and easy to carry (6).

The objectives of the present study were to compare the operation of the Reflotron ${ }^{\circledR}$ dry chemistry system under outdoor-field conditions and under indoorlaboratory conditions, and to compare it with the conventional larger wet chemistry analyzers, with a view to adapting it for on-farm veterinary medical diagnosis.

\section{Materials and Methods}

Animals

Healthy horses $(n=30)$ from the hippodrome in Maputo, Mozambique, were used in the study. The horses were 20 males and 10 females, 3-14 years old and weighing between 400$500 \mathrm{~kg}$. The animals showed no clinical signs and were considered normal and healthy. The climatic temperature during the experiment was $24-32^{\circ} \mathrm{C}$. The Reflotron ${ }^{\circledR}$ was transported in a cushioned box. Prior to operation the analyzer was checked with the checking strips to assure proper function.

\section{Blood samples}

Blood was taken from the jugular vein into heparinized tubes, and plasma was obtained by centrifugation at $600 \mathrm{~g}$ for 10 minutes in the hippodrome. Plasma samples were transported from the field 
to the laboratory in the cold $\left(4^{\circ} \mathrm{C}\right)$ and were analysed within 24 hours.

The plasma of cach horse was analysed three times:

a) in the hippodrome, under field conditions, using the BoehringerMannheim's Reflotron ${ }^{\circledR}$;

b) in the laboratory at the Veterinary faculty using the same Reflotron ${ }^{\circledast}$,

c) in the laboratory at the veterinary faculty using the Cobas Bio analyzer (Hoffman La Roche, Switzerland).

The same Reflotron ${ }^{\circledR}$ analyzer was used indoor and outdoor. Whenever blood analysis was done outdoors, the electricity was obtained from the hippodrome electricity line or from a gas operated generator supplying $220 \mathrm{~V}$ currency.

Blood samples and plasma were transported from the hippodrome to the laboratory in the cold $\left(4-8^{\circ} \mathrm{C}\right)$ and were analysed within 24 hours from the withdrawal.

\section{Blood analysis}

The following analytes were determined. $L$-aspartate : 2 oxoglutarate aminotransferase (EC 2.6.1.1) (7), urea (8), bilirubin (9) and creatinine (10) with the Cobas-Bio analyzer, and with the Boehringer Mannheim's. dry chemistry strips of the Reflotron ${ }^{\circledR}(6)$.

\section{Statistical analysis}

Means, standard deviations and degree of significance between groups were calculated using the SAS users guide ANOVA and the correlation coefficient using the Proc. Corr. (11).

\section{Results}

The means $(\overline{\mathrm{x}})$ and standard deviations (SD) of aspartate aminotransferase, urea, creatinine and bilirubin, measured under field and indoor-laboratory conditions are given in table 1 . The correlation coefficients and significance between the various measurements are shown in figures $1-4$.

As seen in table 1 , no significant differences $(P>0.01)$ between any of the groups were found in the means obtained for any of the analytes using the indoor and outdoor Reflotron ${ }^{\circledR}$ conditions and the Cobas Bio analyser.

Tab. 1 Concentrations of horse blood analytes measured with the dry chemistry Reflotron ${ }^{\circledR}$ analyzer under indoor and outdoor conditions, and with the wet chemistry Cobas-Bio analyzer

\begin{tabular}{lllll}
\hline Analyte & \multicolumn{2}{l}{ Reflotron ${ }^{\circledR}$} & Cobas-Bio \\
\cline { 2 - 4 } & Indoors & Outdoors & & \\
\hline $\begin{array}{c}\text { Aspartate amino- } \\
\text { transferase } \\
(\mathrm{U} / \mathrm{l})\end{array}$ & $274 \pm 68$ & $258 \pm 54$ & $275 \pm 61$ \\
$\begin{array}{c}\text { Urea } \\
(\mathrm{mmol} / \mathrm{l})\end{array}$ & $5.6 \pm 1.6$ & $5.5 \pm 1.6$ & $5.8 \pm 1.5$ \\
$\begin{array}{c}\text { Creatinine } \\
(\mu \mathrm{mol} / \mathrm{l})\end{array}$ & $161 \pm 25$ & $153 \pm 19$ & $155 \pm 26$ \\
$\begin{array}{c}\text { Bilirubin } \\
(\mu \mathrm{mol} / \mathrm{l})\end{array}$ & $37 \pm 13$ & $39 \pm 16$ & $36 \pm 12$ \\
\hline
\end{tabular}

The correlation coefficients between the various measurements, for the various analytes measured are shown in figures $1-4$. Highly significant $(P<0.01)$ correlation coefficients around 0.900 were found for all analytes measured.

\section{Discussion}

Blood analysis using clinical chemical methods is widely used for the better diagnosis of diseases, metabolic disorders and nutritional deficiencies in human and veterinary medicine. The veterinary clinician has often to diagnose his patient outdoors, far away from the laboratory or the hospital.

The time taken to obtain results and the extra costs involved in packaging and transporting the samples with the potential of introducing some mistakes make clinical chemistry less popular among practitioners.

The use of a mobile laboratory to be operated outdoors was first proposed by Bogin $(3,5)$ as a practical solution for veterinary practitioners who work outdoors and depend on laboratory services for a better and more complete diagnosis.

The development of a "mobile (portable) laboratory" for outdoor blood analysis, near the patient, may contribute to a better diagnosis and prognosis, thus avoiding the inconveniences of extra work and cost.

With the development of a "bedside analyzer" in human medicine, based on dry chemistry technology, the use of the relatively small, simple to operate machine was evaluated for its possible use in veterinary medicine.

The present study, evaluating the performance of the Boehringer-Mannheim dry chemistry blood analyzer Reflotron ${ }^{\circledR}$ under outdoor-field conditions, demonstrated the great potential of adapting this equipment for onfarm use in veterinary medicine. The highly significant correlations between the results of the analytes obtained under field conditions and those in the laboratory strongly support this possibility. Similar results obtained for horse blood outdoors in the hippodrome and in the laboratory clearly showed that the Reflotron ${ }^{\circledR}$ can serve as a field blood analyzer, in the zoo and animal parks and farms, as well as other places where animals are raised or kept.

The four analytes studied, aspartate aminotransferase, bilirubin, creatinine and urea are only part of the panel of the tests available and in use for blood analysis with the Reflotron ${ }^{\circledR}$

In the present study, the source of power was either the farm's electricity source or a portable gasoline-operated 
generator supplying 220 Volts, both of which produced similar results.

The study was done in two steps. First, the results of the blood analysis performed with the Reflotron ${ }^{\circledR}$ outdoors on the farm and indoors in the laboratory were compared. Second, these results were then compared to those of conventional wet chemistry analyzers, using the same blood samples in all the tests. The means obtained in all trials were significantly similar $(P<0.01)$, and the correlation coefficients were high in all comparisons, proving that blood analysis of these analytes can be performed on the farm and that the results obtained are valid.

In adapting blood analysis procedures on the farm, better and faster diagnosis can be obtained during
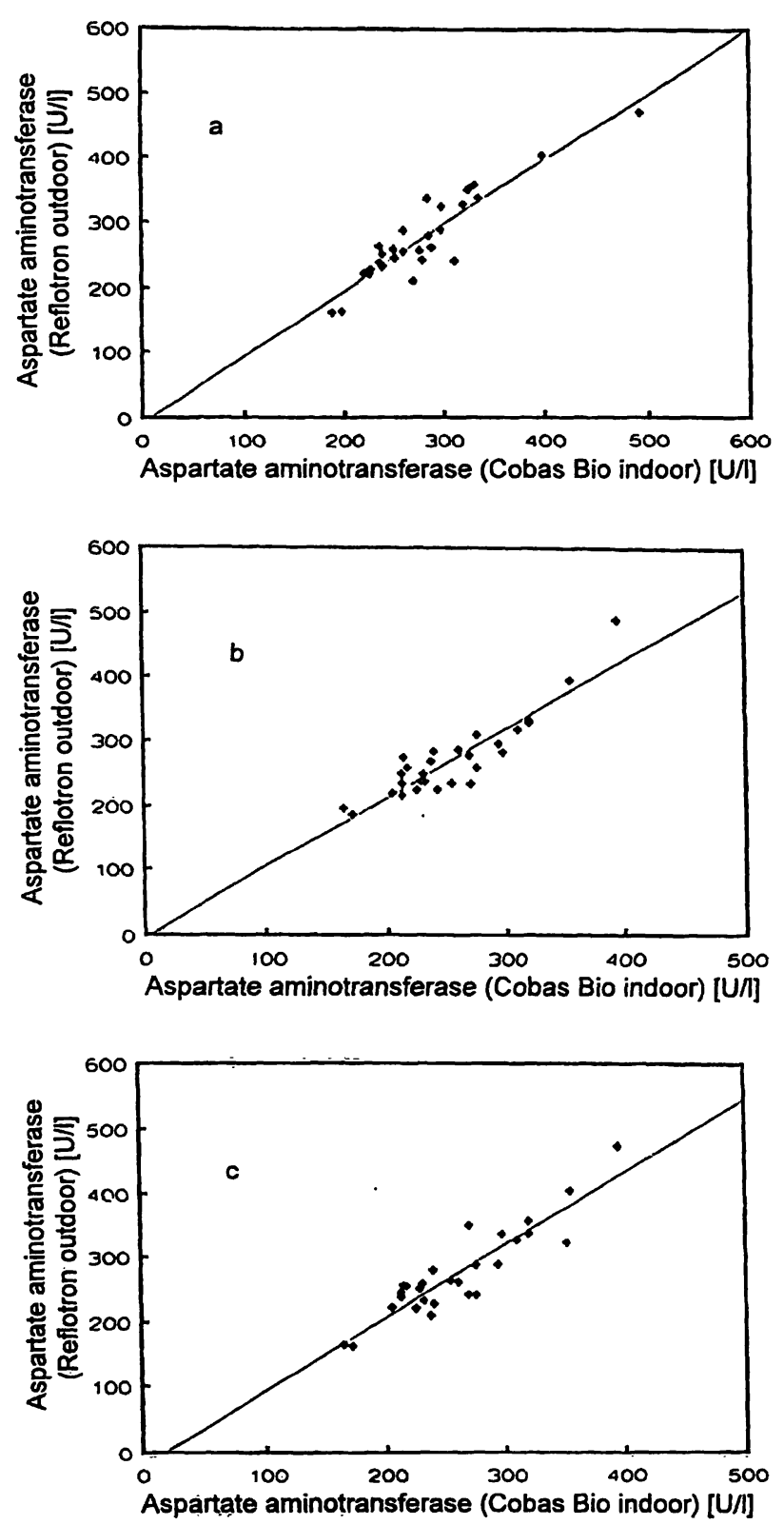

Fig. 1 Regression lines and correlation coefficients for aspartate aminotransferase.

a) $r=0.924 ; y=1.074 x-7.820$
b) $r=0.916 ; y=1.078 x-3.270$
c) $r=0.922 ; y=1.132 x-19.433$ the clinician's visit at a reasonable cost, which under many circumstances does not exceed that of the laboratory and is even less if the savings in time and cost of shipment and added laboratory work are considered. Most important, however, is the fact that the veterinary clinician can perform a more complete diagnosis during investigation of the patient on the farm.

The Reflotron ${ }^{\circledR}$ system enjoys an additional advantage that enables the analysis of whole blood without the need for centrifugation; this saves time and expense and makes blood analysis under outdoor-field conditions easier and more practical. The relatively small size of the Reflotron ${ }^{\circledR}$ and its ability to withstand harsh conditions provides a practical solution for practitioners who work outdoors with the farm animals, and who need the
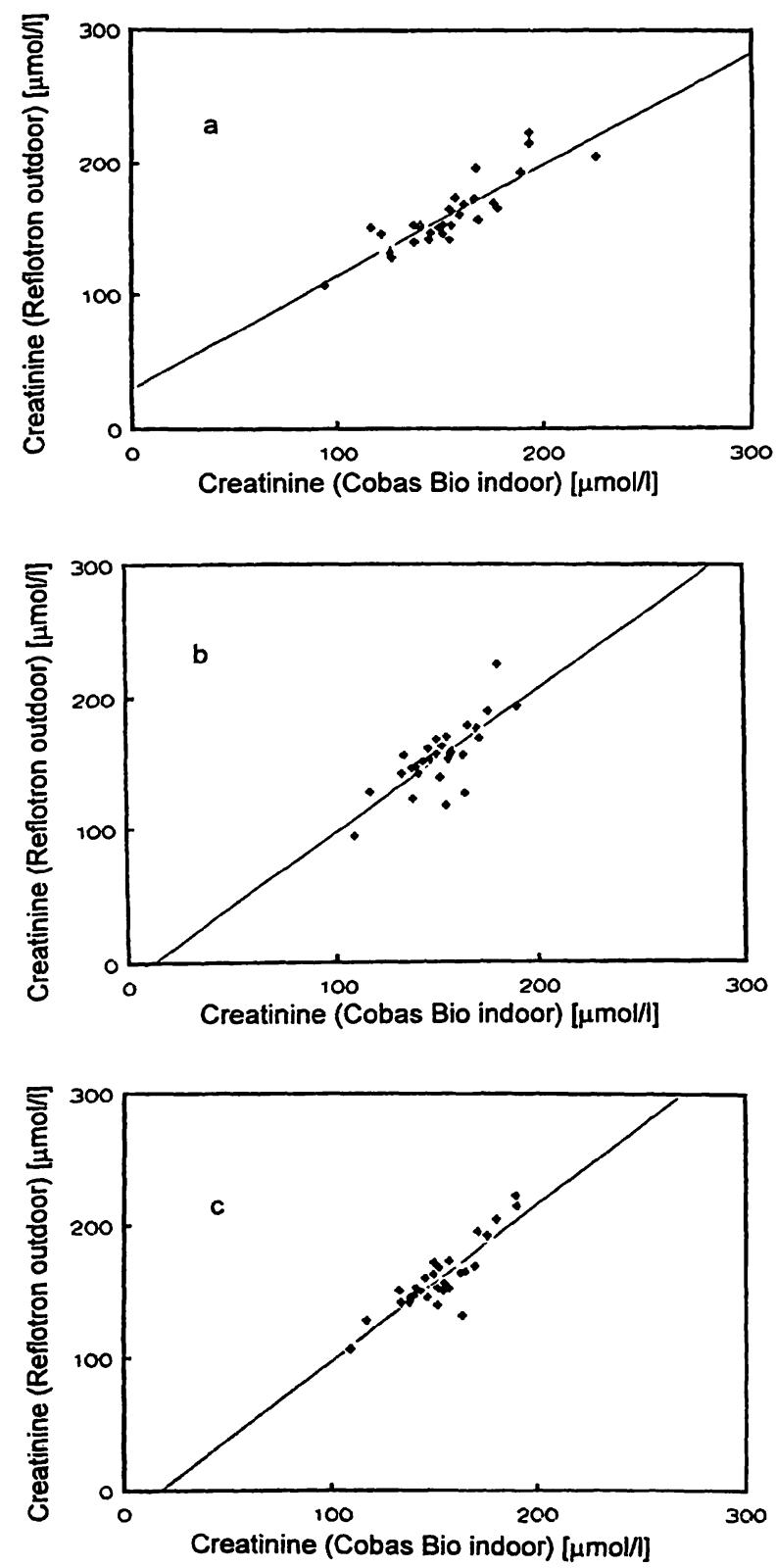

Fig. 2 Regression lines and correlation coefficients for creatinine.
a) $r=0.869 ; y=0.849 x-29.279$
b) $r=0.784 ; y=1.098 x-12.878$
c) $r=0.868 ; y=1.188 x-20.704$ 

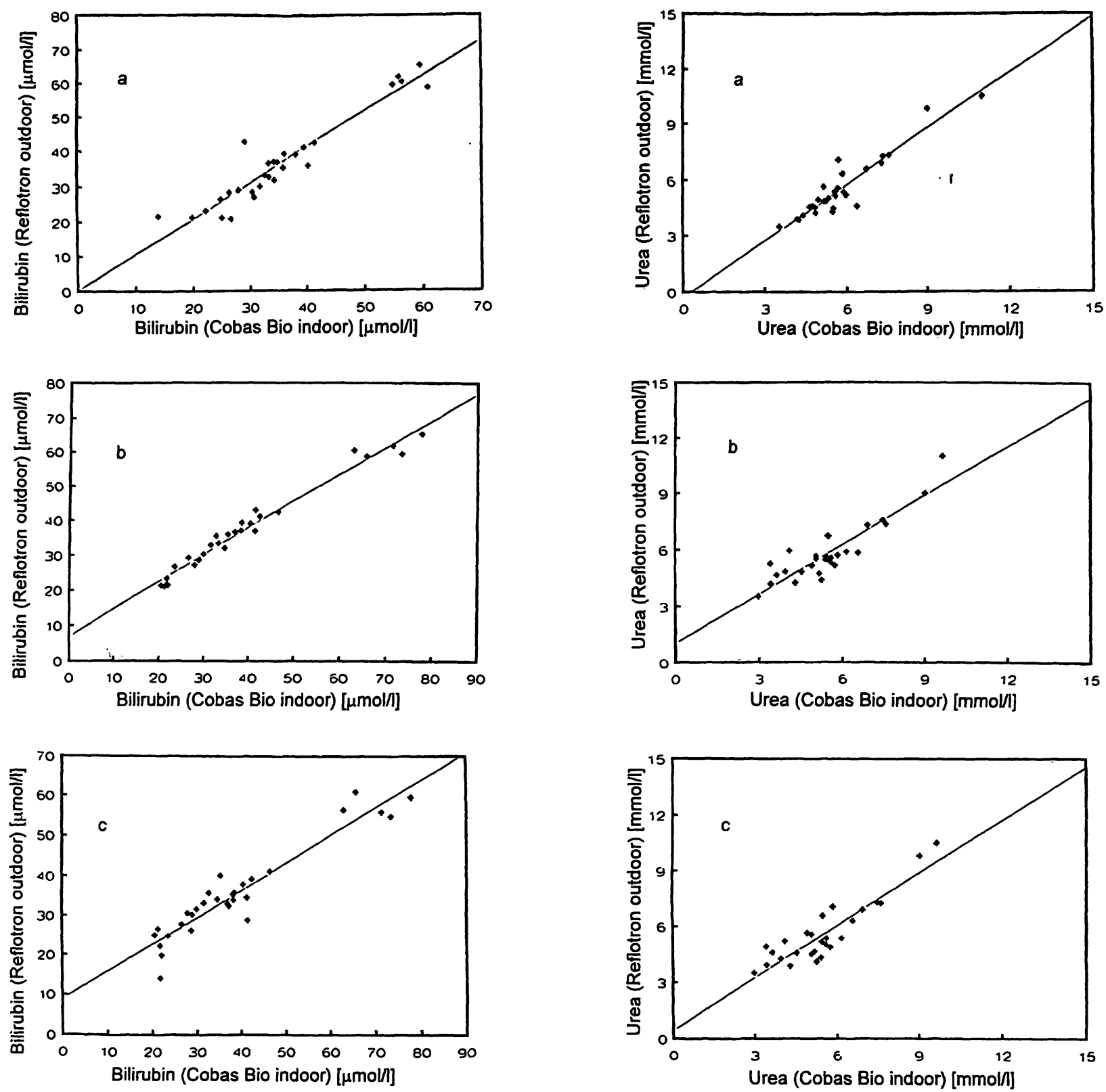

Fig. 3 Regression lines and correlation coefficients for bilirubin. a) $\mathrm{r}=0.952 ; \mathrm{y}=1.038 \mathrm{x}-1.137$

b) $r=0.987 ; y=0.780 x-6.824$

c) $r=0.947 ; y=0.687 x-8.852$

laboratory support for a better and more complete analysis.

The data show that such a system is useful, not only in developed countries, but also - and perhaps even more so - in developing countries that lack the infrastructure of central laboratories as well as transportation and ship-

Fig. 4 Regression lines and correlation coefficients for urea. a) $\mathrm{r}=0.938 ; \mathrm{y}=1.010 \mathrm{x}-0.289$

b) $r=0.894 ; y=0.878 x-1.00$

c) $r=0.897 ; y=0.942 x-0.433$

ping facilities that would allow for fast and speedy analysis.

Other small blood analyzers using dry chemistry technology are available; these are used in veterinary medicine and it may also be possible to use them under outdoor conditions.

\section{References}

1. Bogin E. Handbook for animal clinical chemistry. Kodak Publication USA, 1993.

2. Kaneko JJ. Clinical biochemistry of domestic animals. 3rd ed. New York: Academic Press, 1980.

3. Bogin E. Clinical biochemistry in veterinary medicine - past, present and future. 8th Israel Symposium of Veterinary Medicine. Israel, 1983.

4. Bogin E, Avidar Y, Shenkler S, Israeli B-A, Spiegel N, Cohen R. A rapid field test for the determination of colostral ingestion by calves, based on $\gamma$-glutamyltransferase. Eur $\mathrm{J}$ Clin Chem Clin Biochem 1993; 31:695-701.

5. Bogin E. Clinical enzymological species differences due to metabolic, environmental and nutritional conditions. Enzymes, Tools and Targets, 1988; 6:222-7.

6. Kamlah H. Reflometry, possibilities and limitations of dry chemistry. Boehringer-Mannheim, Publication. Germany, 1984.

7. Bergmeyer HU, Scheibe P, Wahlefeld AW. Optimization of methods for aspartate aminotransferase and alanine aminotransferase. Clin Chem 1978; 24:58-73. 
8. Talke H, Schubert GE. Enaymatische Harnstoffbestimmung in Blut und Serum im optischon Tost nach Warburg. Klin Woclienschr 1965: 43:174-5.

9. Martha J. Walter D, Gerade HG. All ultramicromethod for the detemination of conjugated and colal bilirubin in scrum or plasma. Microchemical J 1970; 15:231-43.

10. Fubiny DL, Ertingshausen (j. Automated reaction rate method for delermination of serum creatinine. Clin Chom 1971: 17:696-700.
11. SAS Institule Inc: SAS user's guide statistics, Version 5. SAS institute Inc. Gury, N.C. USA, 1985.

Received Sceprember 4/November 13, 1095

Corresponding author: I'rol: Dr: Eilan Bogin, Kimron Velerinary Institule, Tol Aviv University School of Medicille, POH 12, Bel Digan, Isracl 
